\title{
Cardiothyreosis in Sub-Saharan Africa (Benin)
}

\author{
Annelie Kerekou-Hode1, Philippe Adjagba², Samiratou Mama Bio², Aude Gaou² \\ ${ }^{1}$ University Clinic of Endocrinology, National University Hospital Center Hubert Koutoukou Manga, Cotonou, Benin \\ ${ }^{2}$ University Cardiology Clinic, National University Hospital Center Hubert Koutoukou Manga, Cotonou, Benin \\ Email: kerekouannelie@yahoo.fr, dotoup@yahoo.fr, audegahou@gmail.com,samiratoumamabio@gmail.com
}

How to cite this paper: Kerekou-Hode, A., Adjagba, P., Bio, S.M. and Gaou, A. (2019) Cardiothyreosis in Sub-Saharan Africa (Benin). Open Journal of Endocrine and Metabolic Diseases, 9, 119-126.

https://doi.org/10.4236/ojemd.2019.911012

Received: October 26, 2019

Accepted: November 27, 2019

Published: November 30, 2019

Copyright $\odot 2019$ by author(s) and Scientific Research Publishing Inc. This work is licensed under the Creative Commons Attribution International License (CC BY 4.0).

http://creativecommons.org/licenses/by/4.0/

\begin{abstract}
This is a retrospective study over a 5-year period from January 1, 2013 to December 31,2018. The diagnosis of cardiothyreosis was retained before clinical signs of hyperthyroidism confirmed to biology by an elevation of T4 and a collapse of ultrasensitive TSH associated with at least one of the following heart failure: insufficiency heart disease, coronary heart failure, rhythm disorder. Sociodemographic, anthropometric, clinical and paraclinical data were analyzed from medical records. Follow-up was evaluated over a period of 6 months to one year after being put on synthetic antithyroids. Results: Of 72 patients seen with hyperthyroidism conditions during the period, we identified 10 cases of cardiothyresis at the departments of Endocrinology and Cardiology of the CNHU/HKM Teaching hospital of Cotonou, Benin. The frequency of cardiothyreosis among hyperthyroidsis was $13.88 \%$. The mean-age for our patients was 50.9 years with bounds from 29 to 79 years. The predominance was female, 8 women for 2 men. A clinical background of high blood pressure is founded in $6 / 10$ patients; $4 / 10$ had a history of hyperthyroidism. All patients had heart failure associated with complete arrhythmia by atrial fibrillation in 6 patients. The multi-modular goiter was found in $5 / 10$ of the patients, the vascular goiter $5 / 10$. Synthetic antithyroids, hygienic-dietary measures and a specific treatment for heart failure were used. The average length of hospital's stay was 7 days. Immediate development is satisfactory with euthyroidism in all patients and improved functional signs. Conclusion: Cardiothyreosis is infrequent in Cotonou. This is a serious complication of hyperthyroidism, which is expensive to manage. Hence the need for early diagnosis and effective treatment of hyperthyroidism.
\end{abstract}

\section{Keywords}

Hyperthyroidism, Cardiothyreosis, Africa

\section{Introduction}

Cardiothyreosis is a heart condition caused by hyperthyroidism. It is a serious 
complication that associates the signs of thyrotoxicosis with heart diseases such as heart failure, coronary heart failure, rhythm disorders or conduction [1]. Some clinical studies have been done in sub-Saharan Africa showing that diagnosis is often made at the caricatural stage [2]-[9]. It is a multidisciplinary condition, which enlists endocrinologist, cardiologist, ophthalmologist, ENT surgeon, and nuclear doctor.

The difficulties of management in Benin may be due to the patient or the technical platform both of medical practitioner and hospital. No studies have been done in Benin. The purpose of our study is to report our experience and compare it with studies achieved in our area.

\section{Methodology}

\subsection{Study Framework}

Benin is a low-income French-speaking country in West Africa. Its population in 2018 was 11.48 million and its gross domestic product (GDP) was US\$10.359 billion. Annual per capita income was US\$870 in 2018 and the poverty rate was $40.1 \%$ in 2015. Life expectancy was 61.17 years in 2018 [10]. Potentially active population (15 - 64 years) represented $52.5 \%$ of the population. In 2012, the urban population was estimated at $45.7 \%$. The guaranteed minimum wage is US\$80 [11].

\subsection{Patients and Method}

This is a retrospective clinical study over a 5-year period from January 1, 2013 to December 31, 2018. Patients have received a clinical examination and biological assessment which have been recorded in medical files hyperthyroidism confirmed to biology by an elevation of T4 $>1.56 \mathrm{ng} / \mathrm{l}(0.7-1.5)$ and a collapse of ultrasensitive TSH $<0.25$ mui/l $(0.25-7)$ associated with at least one of the heart disease: heart failure, coronary artery disease, rhythm disorder. The High Blood Pressure was defined according to WHO 1999 recommendations for Blood pressure > 140/90 mmHg. Patient follow-up was evaluated over a period of 6 months to one year after taking carbimazole (Neomercazole), a synthetized antithyroid, through clinical and biological assessment (TSH and T4 blood tests). Patients' data have been collected: dependent variables were hyperthyroidism and signs of cardiothyreosis, independent variable were sex and age. The analysis of the data was done with the Excel software version 2016.

\section{Results}

\subsection{Clinical Characteristics}

During the study period 72 patients were diagnosed of hyperthyroidism, whom 10 of were suffering from cardiothyreosis. The mean age of the patients were $50.9 \pm 15.60$ years with range of 29 years to 72 years. There were eight women and two men. All patients came from an urban setting. Cardiovascular risk factors found were high blood pressure in 4 patients. Hyperthyroidism had been 
diagnosed in only one patient. Reasons for consultation were dyspnea in 9 cases, lower limb edema 7 cases, weight loss 2 cases and palpitations 4 cases. Frequent clinical manifestations were tachycardia in all patients, exophthalmia in 5 patients, weight loss in 3 patients and thermophobia in one patient (Table 1). All patients were in overall heart failure.

\subsection{Paraclinicals Explorations}

At the paraclinical level, complete arrhythmia by atrial fibrillation was found in the electrokardiogram (EKG) in 6 patients, 4 patients were in sinus rhythm. Tachycardia was consistent in all patients with an average heart rate of $125 \pm 15$ beats/mn.

Cardiac echodoppler had left systolic ventricular dysfunction in 5 patients with a left ventricular ejection fraction (LVEF) less than $40 \%$ and systolic function was pre-tested in 5 patients whose $\mathrm{LVEF} \geq 50 \%$. All patients had left ventricular dilation with an indexed end-diastolic diameter of the left ventricle (IEDDLV) between 32 and $35 \mathrm{~mm} / \mathrm{m}^{2}$. There was no mitral or organic aortic valvular disease.

Thyroid ultrasound performed in 8 patients allowed to identify a nodular goiter in 5 patients and a homogeneous vascular appearance compatible with Basedow's disease in 3 patients.

\subsection{Treatment}

Management consisted of hygienic-dietary measurements in all patients as well as taking a synthetic antithyroid SAT, carbimazole was the most used. The other drugs used are presented in Table 2. All patients were hospitalized and the average length of hospital's stay was 7 days with range of 4 to 14 days.

Table 1. Clinical signs of thyrotoxicosis.

\begin{tabular}{cc}
\hline Signs & Number \\
\hline Tachycardia & 10 \\
Thermophobia & 1 \\
Weigh loss & 3 \\
Exophtalmia & 5 \\
\hline
\end{tabular}

Table 2. Therapeutic measures.

\begin{tabular}{cc}
\hline Therapeutic & Number \\
\hline Diet and lifestyle measures & 10 \\
Synthetized antithyröids & 10 \\
Cardiac glycosides and diuretics & 9 \\
Cardiac glycosides & - \\
Diuretics & 1 \\
Converting enzyme inhibitors & 6 \\
Beta-blockers & 4 \\
Calcium antagonist & 3 \\
Anticoagulation treatment & 9 \\
\hline
\end{tabular}




\subsection{Evolution}

Positive evolution in all patients with a regression of signs of heart failure, stabilization of hemodynamic state and heart rate, weight gain and regression of thyrotoxicosis.

\section{Discussion}

\subsection{Limits and Constraints}

We conducted a retrospective study with hospital recruitment, which is a recruitment bias in terms of prevalence and incidence assessment. Not all desired information was always collected in medical files. Management issues were primarily diagnostic delays and difficulties in carrying out additional examination which were the responsibility of patients. Therefore, this recruitment was low 72 cases of hyperthyroidism in 5 years as in most sub-Saharan studies [2]-[8]. This may result in poor health coverage in our countries or poor access to care, including lack of knowledge of the discipline of endocrinology by patients and cultural beliefs that guide patients to tradi-practitioners. In our study all patients come from the urban environment, highlighting the difficulty of making so-called modern medicine accessible in rural areas due to financial and geographical inaccessibility. The guaranteed minimum wage in Benin is $\$ 80$, a specialized medical consultation at the hospital is $\$ 14$, the cost of the minimum hornomal check-up is $\$ 42$ and Echocardiography and cardiac doppler ultrasound is $\$ 30$. Despite the financial difficulties all our patients were able to make the necessary pretherapeutic paraclinical assessments. The hospital prevalence of cardiothyreosis is $13.88 \%$ among the population of patients with hyperthyroidism in our study. In sub-Saharan studies this frequency ranges from $9.8 \%$ to $46.66 \%$, reflecting late and last resort consultation of patients. This attitude is not specific to hyperthyroidism. In Morocco, Hattaoui reported a prevalence of $16.6 \%$ similar to those reported in Subsharian Africa [12]. This prevalence is $1 \%$ among patients with hyperthyroidism in Minnesota in the USA [13]. The average age of cardiothyreosis occurs in the 4th and 5th decade (Table 3) as is Hattaoui in Morocco [12]. Female predominance was classically found in our study, as were most authors in sub-Saharan Africa [2]-[9].

\subsection{Clinical Characteristics}

Patients were mostly at the pictural stage of cardiothyreosis. Thus having signs of thyrotoxicosis (tachycardia, thermophobia weight loss) and cardiac complications were dominated outside of heart failure by rhythm disorders with 6 cases of complete arrhythmia by atrial fibrillation. (Table 3) These same complications have been reported by the authors in sub-Saharan Africa (Table 3). During clinical hyperthyroidism, tachycardia, vascular erethism, increased pulse draught are frequent, even constant [14]. The pathophysiological explanations of thyrotoxic crisis in hyperthyroid patients are poorly understood. Several factors appear to be involved, more or less simultaneously [15]: 
Table 3. Comparative table of Subsaharan studies.

\begin{tabular}{|c|c|c|c|c|c|c|c|c|c|}
\hline & 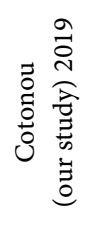 & 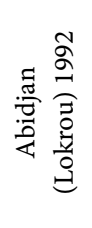 & 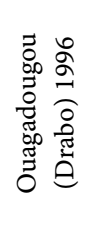 & 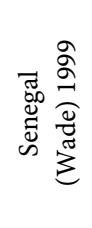 & 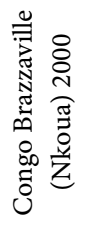 & 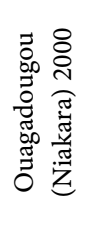 & 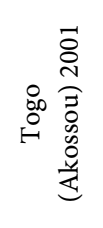 & 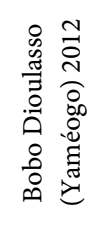 & 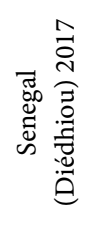 \\
\hline Duration & 5 ans & 4 ans & 4 ans & 3 ans & 9 ans & 6 ans & 4 ans & 1 an & 4 ans \\
\hline Number of case & 10 & 7 & 10 & 16 & 20 & 32 & 30 & 14 & 150 \\
\hline Prevalence (\%) & 13.88 & 14 & 22.2 & 10.52 & 12.6 & - & 36.58 & 33.3 & 9.8 \\
\hline Mean-age (years) & 50.9 & 41.14 & 44 & 48 & 43 & 43.3 & - & 53.57 & 42.6 \\
\hline Average duration (months) & 12 & 20.10 & - & - & - & - & - & - & 27 \\
\hline Sex (dominance) & $\mathrm{F}$ & $\mathrm{F}$ & $\mathrm{F}$ & $\mathrm{F}$ & $\mathrm{F}$ & $\mathrm{F}$ & $\mathrm{F}$ & $\mathrm{F}$ & $\mathrm{F}$ \\
\hline High BP background & 6 & - & 2 & 4 & 6 & - & - & 9 & $31.3 \%$ \\
\hline Hyperthyroidism background & 1 & - & - & - & - & - & - & 3 & - \\
\hline Heart disease background & 1 & - & - & 7 & - & 5 & - & - & $10 \%$ \\
\hline \multicolumn{10}{|l|}{ Aetiology } \\
\hline - Multinodular goiter & 5 & - & 4 & 2 & 8 & - & 3 & Not fin & - \\
\hline - Basedow's disease & 5 & - & 4 & 9 & 8 & - & 25 & - & - \\
\hline - Toxic adenoma & - & - & 2 & 1 & 2 & - & 2 & 1 & $18 \%$ \\
\hline - Thyroid cancer & - & - & - & - & 2 & - & & & - \\
\hline Heart failure & 10 & 3 & 3 & 12 & 19 & 22 & $57.14 \%$ & 14 & $62 \%$ \\
\hline Complete arrhytmia by atrial fibrillation & 6 & 2 & 3 & 9 & 7 & 13 & $28.57 \%$ & 8 & $38 \%$ \\
\hline Coronary artery disease & 1 & 3 & 2 & - & - & - & $21.43 \%$ & 6 & $8 \%$ \\
\hline \multicolumn{10}{|l|}{ Therapeutics measures } \\
\hline - Synthetized antithyroids & 10 & Yes & 9 & Yes & Yes & Yes & Yes & Yes & Yes \\
\hline - Dietary and hygienics procedures & 10 & Yes & - & - & - & Yes & Yes & Yes & Yes \\
\hline - Diuretics ans cardiac glycosides & 9 & Yes & - & - & - & 22 & Yes & Yes & Yes \\
\hline - $\beta$ eta-blockers & 4 & Yes & - & - & - & 10 & Yes & Yes & Yes \\
\hline - Anticoagulation treatment & 9 & - & - & - & - & 22 & - & & - \\
\hline - Nitrates & - & - & - & - & - & - & Yes & - & - \\
\hline - Converting enzyme inhibitors & 6 & - & - & - & - & - & Yes & Yes & - \\
\hline - Calcium antagonist & 1 & - & - & - & - & - & Yes & Yes & - \\
\hline - Platelets aggregation inhibitors & - & - & - & - & - & - & & Yes & - \\
\hline Surgery & - & - & 4 & - & - & - & 1 & - & - \\
\hline Average hospital stay & $7 \mathrm{jrs}$ & - & - & - & - & 18.3 & - & 23.57 & - \\
\hline \multicolumn{10}{|l|}{ Evolution } \\
\hline - Positive & 10 & - & - & - & - & 9.7 & 29 & - & - \\
\hline - Death & - & - & 1 & - & - & 1 & 1 & 1 & - \\
\hline
\end{tabular}

- High circulating levels of thyroid hormones: although this may appear to be a palisade, circulating thyroid hormone levels are not much higher during the thyroid attack than in stable hyperthyroid patients;

- Quick and sudden increase in thyroid hormone levels: this would be the primary factor in the occurrence of the crisis, much more significant than the absolute value of circulating thyroid hormone levels; 
- Hyperactivity of the sympathetic nervous system: the sympathetic nervous system was involved in the genesis of the thyroid attack due to the similar symptomatology between thyrotoxicosis and the catecholaminergic crisis and the beneficial effect of the administration of blockers in these two pathologies;

- Amplification of cellular response to thyroid hormones: this mechanism has been mainly evoked during pathological situations, such as sepsis, hypoxia, hypovolemia and metabolic acidosis.

During thyrotoxicosis, preload is frequently increased through stimulation of the renine-angiotensin-aldosterone system and positive regulation of erythropoietin secretion, without this variation being significantly noticeable. Nevertheless, it maintains a blood volume in relation to tachycardia and thus induces an increase in cardiac output. The increase in myocardial contractility remains controversial. It is believed to be related to a change in the synthesis of the heavy myosin chain, an increase in the transcription of the gene encoding ATPase, and an increase in the use of glucose and calcium resulting in reversible "cardiomyopathy" [16]. The main etiologies of hyperthyroidism set were multinodular goiter and Basedow disease in our study. These two etiologies are the most frequently recognized in the literature [15]. Our explorations were limited to thyroid ultrasound; cytopuncture was not performed in patients who had a thyroid nodule. Similarly we do not have the scan which limits etiological research.

\subsection{Treatment}

The treatment was essentially medical in our study and involved hospitalization in all cases with an average hospital stay of 7 days. Medical treatment was based on carbimazole and supportive treatment following the complications of each patient. This attitude was that of most authors in sub-Saharan Africa. We did not use surgical treatment. The management of heart failure in cardiothyreosis has been classic. It used hygienic-dietary measures and digital-diuretic treatment associated with vasodilators and beta-blockers. This is a treatment regimen used by most authors. High blood pressure was treated with conversion enzyme inhibitors or calcium inhibitors based on the hemodynamic state of patients. In our study, the treatment of atrial fibrillation was based on beta-blockers alone or associated with cardiac glycosides. He routinely used anticoagulants to prevent thromboembolic complications that are quite common in cardiothyreosis [2]. The evolution of cardiothyreosis in our series, differs little from the results described in the literature. Positive evolution in all patients with a stabilization of hemodynamic state at a near future is between 4 and 6 weeks. Majority of patients were lost after 18 months. Only one achieved a complete follow-up treatment. This finding has been reported by other authors in sub-Saharan Africa [2] [6]. This loss can be put on the account of the financial accessibility to medicines such as carbimazole or the poor awareness on the chronicity of this condition. 


\section{Conclusion}

Cardiothyreosis is a serious complication of hyperthyroidism that can cause morbidity and mortality. Prevention involves early diagnosis of hyperthyroidism and effective treatment. The unfavourable socio-economic level may limit hormonal dosages and inhibit this prevention. Cardiothyreosis remains a health problem in developing countries.

\section{Acknowledgements}

To the statistician ASSOGBA Brice.

\section{Conflicts of Interest}

The authors declare no conflicts of interest regarding the publication of this paper.

\section{References}

[1] Valcke, J. (1987) De lacharriere O. Cardiothyréoses. La revue du praticien, 37, 24562432.

[2] Yaméogo, A.A., Yaméogo, N.V., Compaoré, Y.D., Ouédraogo, T.L. and Zabsonré, P. (2012) La cardiothyréose au centre hospitalier universitaire de Bobo-Dioulasso, Burkina Faso. Pan African Medical Journal, 11, 38.

[3] Wade, B., Tiendrébeogo, A. and Charles, D. (1999) Les cardiothyréoses. A propos de 16 observations sénégalaises. Médecine d Afrique Noire, 46, 251-257.

[4] Niakara, A., Nébié, L. and Drabo, Y. (2000) La cardiothyréose: Étude rétrospective de 32 cas dans les services de cardiologie et de médecine interne à Ouagadougou, Burkina Faso (1993-1998). Bulletin de la Société de Pathologie Exotique, 93, 25-28.

[5] Lokrou, A. and Koffi, J. (1992) Cardiothyréose compliquant la maladie de Basedow. Etude de 7 cas à Abidjan. Médecine d Afrique Noire, 39, 312-314.

[6] Akossou, S., Napporn, A., Goeh-Akue, E., Hillah, A., Sokpoh-diallo, K., Soussou, B. and Amedegnato, D. (2001) Les difficultés de la prise en charge de la thyréotoxicose en Afrique noire: L'expérience du Togo. In: Annales dendocrinologie: 2001, Masson, 516-520.

[7] Nkoua, J., Mban, B., Bandoho-Mambo, A., Aba, G. and Bouramoue, C. (2000) Cardiothyreoses: Fréquence, étiologies et aspects nosologiques à propos de 20 cas. Médecine d Afrique Noire, 47, 450-454.

[8] Drabo, Y., Kabore, J. and Ouandaogo, J. (1996) Les cardiothyréoses à Ouagadougou: A propos de 10 cas. Médecine d' Afrique Noire, 43, 615-618.

[9] Diédhiou, D., Sow, D., Lèye, M., Diallo, I., Bodian, M., Ndoure, M., Bouary, E., Mbaye, M.N., Sarr, A. and Diop, S. (2017) Cardiothyreosis: Risk Factors and Clinical Profile. Open Journal of Internal Medicine, 7, 1-11. https://doi.org/10.4236/ojim.2017.71001

[10] Benin: Country at a Glance. https://donnees.banquemondiale.org/pays/benin

[11] Institue Nationale de la Statistique et de l'Analyse Economique du Bénin (2012) Tableau de bord social. https://www.insae-bj.org/statistiques/statistiques-demographiques

[12] El Hattaoui, M., Charei, N., Mouniri, M. and Diouri, A. (2009) Cardiothyréoses dans 
la région de Marrakech. À propos de 36 cas. In: Annales de cardiologie et d angeiologie: 2009, Elsevier, Amsterdam, 135-138.

https://doi.org/10.1016/j.ancard.2008.07.006

[13] Little, J.W. (2006) Thyroid Disorders. Part I: Hyperthyroidism. Oral Surgery, Oral Medicine, Oral Pathology, Oral Radiology, and Endodontology, 101, 276-284.

https://doi.org/10.1016/j.tripleo.2005.05.069

[14] Biondi, B., Palmieri, E.A., Lombardi, G. and Fazio, S. (2002) Effects of Thyroid Hormone on Cardiac Function-The Relative Importance of Heart Rate, Loading Conditions, and Myocardial Contractility in the Regulation of Cardiac Performance in Human Hyperthyroidism. The Journal of Clinical Endocrinology \& Metabolism, 87, 968-974. https://doi.org/10.1210/jcem.87.3.8302

[15] Thirion, M., Percheron, S. and Mira, J.-P. (2006) Thyrotoxicose. Réanimation, 15, 497-505. https://doi.org/10.1016/j.reaurg.2006.10.002

[16] Toft, A. and Boon, N. (2000) Thyroid Disease and the Heart. Heart, 84, 455-460. https://doi.org/10.1136/heart.84.4.455 